\title{
À volta do casamento do infante D. Pedro
}

Around infant D. Pedro's marriage

\section{Douglas Mota Xavier de Lima}

\section{(2) OpenEdition \\ Journals}

Edição electrónica

URL: http://journals.openedition.org/medievalista/1278

DOI: 10.4000/medievalista. 1278

ISSN: 1646-740X

\section{Editora}

Instituto de Estudos Medievais - FCSH-UNL

\section{Refêrencia eletrónica}

Douglas Mota Xavier de Lima, «À volta do casamento do infante D. Pedro », Medievalista [Online],

21 | 2017, posto online no dia 01 junho 2017, consultado no dia 03 maio 2019. URL : http:// journals.openedition.org/medievalista/1278; DOI : 10.4000/medievalista.1278

(C) IEM 
Título / Title: À volta do casamento do infante D. Pedro / Around infant D. Pedro's marriage

Autor(es) / Author(s): Douglas Mota Xavier de Lima

Universidade / University: Universidade Federal do Oeste do Pará

Faculdade e Departamento / Unidade de Investigação - Faculty and Department /

Research Center: Instituto de Ciências da Educação, Programa de Ciências Humanas

Código Postal / Postcode: 68040-470

Cidade / City: Santarém

País / Country: Brasil

Email Institucional / Institutional email: douglas.mxl@ufopa.edu.br

Fonte: Medievalista [Em linha]. Direc. Bernardo Vasconcelos e Sousa. Lisboa: IEM.

Disponível em:

http://www2.fcsh.unl.pt/iem/medievalista/MEDIEVALISTA21/lima2106.html

ISSN: 1646-740X

Data recepção do artigo / Received for publication: 23 de Junho de 2016

Data aceitação do artigo / Accepted in revised form: 21 de Outubro 2016 


\section{Resumo}

Tendo como base o célebre artigo de António Joaquim Dias Dinis acerca da união matrimonial do rei D. Duarte, propõe-se uma abordagem de um outro enlace igualmente importante para a coroa de Avis, o casamento do infante D. Pedro de Portugal com D. Isabel de Urgel. Tal consórcio é analisado no contexto das relações diplomáticas ibéricas, em especial entre Portugal e Aragão, e da política matrimonial avisina das primeiras décadas do século XV. Por tratar-se de um matrimónio tradicionalmente visto como negativo para o reino, em virtude das disputas pela e durante a regência entre D. Pedro e D. Leonor de Aragão, rainha de Portugal e membro de uma família rival da esposa do infante, analisa-se o enlace propondo uma revisão historiográfica e uma nova leitura da documentação sobre as relações luso-aragonesas dos anos de 1420 e de 1430.

Palavras-chave: Infante D. Pedro; Dinastia de Avis; Relações luso-aragonesas; Casamento.

\section{Abstract}

Having as basis the famous article written by António Joaquim Dias Dinis concerning D. Duarte's marriage, it is proposed an approach of another connection equally important for the crown of Avis, the marriage of the infant D. Pedro from Portugal with D. Isabel of Urgel. Such consortium is analyzed in the context of the Iberian diplomatic relationships, especially between Portugal and Aragon, and of the matrimonial avisin politics of the first decades of the 15th century. Being traditionally seen as negative for the kingdom because of the disputes, for and during the regency, among D. Pedro and D. Leonor of Aragon, queen of Portugal and member of a rival family of the infant's wife, the marriage is analyzed proposing a historiographical revision and a new reading of the documents about the Portuguese-Aragonese relationships from the 1420's and 1430 's.

Keywords: D. Pedro, Infant; Avis Dynasty, Portuguese-Aragonese relationships; marriage. 


\section{ڤ}

\section{À volta do casamento do infante D. Pedro / Around Infant D. Pedro's marriage}

\section{Douglas Mota Xavier de Lima}

Há pouco mais de quarenta anos o historiador português António Joaquim Dias Dinis publicava, na Revista Portuguesa de História da Universidade de Coimbra, o célebre artigo "À volta do casamento do infante D. Duarte (1409-1428)" ". As páginas de Dias Dinis permanecem como principal reflexão acerca do casamento do Eloquente, expressão ímpar da política ibérica e matrimonial de D. João I. Ocorrido no mesmo ano, o enlace do infante D. Pedro também envolveu as relações ibéricas, porém ainda se mostra envolto em lacunas. Dito isso, aproveitamos as quatro décadas do belo estudo de Dias Dinis para tecer alguns apontamentos sobre o casamento de D. Pedro. Todavia, antes de discutir diretamente o enlace, é importante apresentar considerações acerca do próprio Infante na historiografia e da política matrimonial de D. João I.

Mesmo com os inúmeros estudos sobre o período avisino realizados nos últimos séculos, a figura do infante D. Pedro permanece ofuscada. Sexto filho de D. João I e quarto da união com D. Filipa de Lancaster, D. Pedro nasceu em 09 de dezembro de 1392, e tornou-se duque de Coimbra na sequência da conquista de Ceuta (1415). Foi um dos expoentes da aclamada Ínclita Geração, em grande parte devido à viagem pela Cristandade (1425-1428), aos seus escritos e traduções e à actuação política em Portugal. Foi regente do reino (1439-1448) durante a menoridade de D. Afonso V,

\footnotetext{
${ }^{1}$ DINIS, António Joaquim Dias - "À volta do casamento de D. Duarte. (1409-1428)". in Separata da Revista Portuguesa de História. Coimbra: Universidade de Coimbra, Tomo XV, 1974, pp. 5-70.
} 
sendo morto na Batalha de Alfarrobeira (1449). Com esta síntese biográfica, verifica-se que a personagem teve a sua vida marcada pelos espaços do poder e que os seus feitos ficaram registados na história portuguesa ${ }^{2}$, no entanto, se a memória foi considerada, a face humana de D. Pedro continua um tanto obscura.

Carente de um estudo biográfico aprofundado ${ }^{3}$, os vestígios acerca da vida do Infante permanecem muito dispersos. Elementos relativos aos traços físicos e à formação durante a infância e juventude são raros, sendo o recurso frequente a adoção da descrição de Rui de Pina, escrita no século $\mathrm{XVI}^{4}$. Mesmo com tais carências é possível estabelecer três eixos principais dos estudos sobre D. Pedro: o primeiro é relativo ao livro de viagens - Libro del Infante D. Pedro de Portugal -, o qual the proporcionou o epíteto de "Infante das Sete Partidas"; o segundo está relacionado com os aspectos culturais - traduções e escritos -, sendo o livro da Virtuosa Benfeitoria e a Carta de Bruges, os ícones dessa actuação; por fim, o conjunto de sua acção política, que se

\footnotetext{
${ }^{2}$ Manuel Simões assim descreve o Infante: "Foi membro destacado da chamada Ínclita Geração, cultor de mérito no âmbito das ciências e das letras, e elemento preponderante da cultura medieval portuguesa, responsável porventura pelo alvorecer das ideias humanistas em Portugal, na sequência das suas muitas viagens que o tornaram conhecido como Infante das "Sete Partidas". (SIMÕES, M. - "Dom Pedro". in LANCIANI, Giulia; TAVANI, Giuseppe (org.) - Dicionário da Literatura Medieval Galega e Portuguesa. Lisboa: Caminho, 1993, p. 529).

${ }^{3}$ A biografia do Infante foi prometida por Veiga Simões no início do século XX, mas não chegou a ser publicada, visto que o autor faleceu em 1954. Até o momento, uma obra global da vida de D. Pedro permanece aguardando seu investigador, existindo apenas a recente e sucinta obra de Alfredo Pinheiro Marques (Vida e Obra do Infante D. Pedro. Lisboa: Gradiva, 1996). Sabemos, contudo, que a Professora Doutora Ana Maria Rodrigues (da Universidade de Lisboa) prepara uma biografia do infante a ser lançada nos próximos anos.

${ }^{4}$ Rui de Pina escreveu um capítulo dedicado a descrever o Infante, intitulado "Das feições, costumes e virtudes do Infante D. Pedro". Neste, assim caracteriza D. Pedro: "O Infante D. Pedro por certo foi um singular Principe, dino de louvor entre os bons e louvados Principes que no mundo em seu tempo houve, homem de grande corpo, e de seus membros em todo bem proporcionado, e de poucas carnes; teve o rosto comprido, nariz grosso, olhos um pouco moles, os cabellos da cabeça crespos, e os da barba algum tanto ruivos como inglez; seu andar a pé era vagaroso e com grande repouso, suas palavras eram graciosas, com doce órgão de dizer, e nas sentenças mui graves e sustanciaes, e quando alguma sanha o tocava era sua cara mui temerosa, e porém não lhe durava muito, cá por siso ou condição natural, logo se lembrava de mansidão e temperança; foi algum tanto culpado em credeiro e vingativo, ainda que o desejo de vingança pareceu que não foi n'elle de grande e vicioso ardor, pois dilatou e temperou a que teve em sua mão, que para sua vida fôra mui segura e necessária" (PINA, Ruy de - Chrónica de El-Rei D. Affonso V. Biblioteca de Clássicos Portugueses. Introdução de Gabriel Pereira. Lisboa: Escriptorio, 1901, Vol. 2, Capítulo CXXV, p. 110). A descrição do cronista português é marcante, contudo há outra exposição que não convém ser descartada. Trata-se da versão latina da conquista de Ceuta, escrita por Mateus Pisano, por volta de 1460 e somente editada em 1790. No texto, assim o duque de Coimbra é descrito: "D. Pedro, nascido em segundo lugar, foi desde a infância muito dedicado ao estudo das sagradas letras e das outras boas artes, e tanto, ainda em moço, se distinguiu por seu espírito de justiça, por sua liberalidade, comedimento e valor, que atraía sobre si as vistas de todos, dando esperança de vir a ser um grande príncipe" (PISANO, Mateus de - Livro da Guerra de Ceuta. Ed. Roberto Corrêa Pinto. Lisboa: Academia das Sciências de Lisboa, 1915, p. 12).
} 
concentra no período em que o mesmo foi regente de Portugal (1439-1448). Ao longo das nossas pesquisas sobre o Infante, as lacunas relativas à viagem nos chamaram atenção, fazendo ainda notar o silêncio acerca do casamento.

Ao lidar com as crónicas escritas sobre a primeira metade do século $\mathrm{XV}$, poucos são os dados relativos à vida de D. Pedro. A Crónica de D. João I abarca as primeiras décadas de Quatrocentos, centrando-se no processo da revolução de Avis e nas figuras de D. João e do Condestável do reino, Nuno Álvares Pereira, informando apenas sobre o nascimento dos filhos do Mestre e a relação familiar ${ }^{5}$. A Chronica do Condestabre de Portugal, por sua vez, fixa-se na figura de Nuno Álvares, citando brevemente o Infante cavalgando ao lado de D. João I após a conquista de Ceuta ${ }^{6}$. A Chronica dos feitos, vida, e morte do Iffante Sancto Dom Fernando que morreo em Fez não traz informações sobre o duque de Coimbra. As crónicas de Zurara, com destaque para a Crónica da Tomada de Ceuta ${ }^{8}$, apresentam mais relatos sobre D. Pedro, contudo, pelo facto de o cronista, servidor da casa de D. Henrique, escrever no contexto de Alfarrobeira, o texto limita a participação do Infante no ataque de $1415^{9}$. Acrescenta-se que, mesmo trazendo mais vestígios acerca das acções de D. Pedro, esta crónica informa pouco sobre a sua juventude. A Crónica do Conde Dom Pedro de Menezes apresenta algumas menções ao Infante, sendo interessante por mostrá-lo ajudando na defesa do

\footnotetext{
${ }^{5}$ LOPES, Fernão - Crónica de D. João I. Segundo o códice no 352 do Arquivo Nacional da Torre do Tombo. Introdução de Humberto Baquero Moreno. Prefácio de António Sérgio. Porto: Livraria Civilização, 1983, vol. 2, Capítulo CXLVIII.

${ }^{6}$ CHRONICA DO CONTESTABRE de Portugal Dom Nuno Alvarez Pereira. Ed. F. França Amado. Coimbra, 1911, pp. 202-203.

${ }^{7}$ ÁLVARES, Frei João - Chronica dos feitos, vida, e morte do Iffante Sancto Dom Fernando que morreo em Fez. Ed. António Ribeiro. Lisboa, 1577.

${ }^{8}$ ZURARA Gomes Eanes de - Crónica da Tomada de Ceuta. Ed. Reis Brasil. Mem Martins: Publicações Europa-América, 1992.

${ }^{9}$ Sobre a discussão acerca da crónica de Zurara em relação ao Infante, ver: MARQUES, Alfredo Pinheiro - A maldição da memória do Infante Dom Pedro e as origens dos descobrimentos portugueses. Figueira da Foz: Centro de Estudos do Mar, 1994; Vida e Obra do Infante D. Pedro. Lisboa: Gradiva, 1996; QUEIRÓS, Silvio Galvão de - "Pera Espelho de Todollos Uiuos". A imagem do Infante D. Henrique na Crônica da Tomada de Ceuta. Niterói: Programa de Pós-Graduação em História da Universidade Federal Fluminense, 1997. Dissertação de Mestrado.
} 
reino perante possíveis ataques de Castela ${ }^{10}$, e por indicar um zelo de D. João I com o filho que queria participar na campanha de socorro enviada a Ceuta ${ }^{11}$.

Para além dos textos cronísticos citados, os principais documentos acerca do Infante provêm da chancelaria régia e demarcam a formação do seu património em torno de Coimbra, concentrando-se no período regencial. Todavia, essa especificidade das fontes prejudica uma visão global e mais detalhada - itinerários, contactos, actuação na Corte - do seu percurso de vida ${ }^{12}$.

Assim como D. João I e D. Duarte, D. Pedro também se afirmou como escritor de importantes tratados e epístolas, além de actuar como tradutor. A sua obra mais conhecida é a Virtuosa Benfeitoria ${ }^{13}$, e entre os textos destinados ou oferecidos ao irmão e futuro rei, soma-se o Livro dos Ofícios $^{14}$. Por fim, uma das faces mais citadas

${ }^{10}$ ZURARA, Gomes Eanes de - Crónica do Conde Dom Pedro de Menezes. Ed. José Adriano de Freitas Carvalho. Porto: Programa Nacional De Edições Comemorativas dos Descobrimentos Portugueses, 1988, Capítulo LXXII, p. 246.

${ }^{11} \mathrm{O}$ cronista menciona que D. Pedro foi pelas suas terras levando notícias da organização da campanha de auxílio a Ceuta. O mesmo tinha muita vontade de integrar a campanha, chegando a tentar disfarçar-se para embarcar nos navios que partiriam. No entanto, após ser descoberto o Infante foi requerer permissão do rei para seguir com as tropas. Eis a descrição de Zurara sobre a resposta de D. João I: "entam juntamente com o infante Eduarte seu Irmao requererom a seu Padre licença, a qual the de todo foi denegada, mandando, que todavia o Infante Dom Enrique partisse logo com a frota, como ante tinha determinado; e que o Infante Eduarte, e o Infante Dom Pedro se fossem ambos ao Algarve, e hy ouvessem seu conselho, e o que lhes parecesse, pozessem em obra". Por mais que o trecho indique que somente D. Henrique foi designado para chefiar a campanha, em nenhum momento transparece que o rei visava prejudicar de alguma forma D. Pedro. Antes parece que D. João buscou, nesse contexto, proteger os dois filhos mais velhos de qualquer incidente na campanha africana. Assim, afirma-se a ideia de zelo do rei que procurava resguardar os herdeiros diretos da coroa e manter a proteção militar do reino. ZURARA, Gomes Eanes de - Crónica do Conde Dom Pedro de Menezes..., Capítulo LXXVII, pp. 258259.

${ }_{12}$ Baquero Moreno, por exemplo, publicou um estudo acerca dos itinerários do Infante, no entanto, se restringiu ao período da regência ("Os itinerários do Infante D. Pedro 1438-1449". in MORENO, Humberto Carlos Baquero - O Infante D. Pedro, Duque de Coimbra: itinerários e ensaios históricos. Porto: Universidade Portucalense, 1997, pp. 169-195). Na mesma obra, Moreno considera que o largo período entre o nascimento e a morte de D. Duarte constitui uma etapa da vida do Infante "que mal se conhece e tantas vezes se distorce em função de uma atitude raras vezes isenta de algum preconceito" ("O Infante D. Pedro e o ducado de Coimbra". in MORENO, Humberto Carlos Baquero - O Infante D. Pedro, Duque de Coimbra..., p. 25).

${ }^{13}$ Veja-se DOM PEDRO, Infante - Livro da Vertuosa Benfeytoria. Ed. Adelino de Almeida Calado. Coimbra: Universidade de Coimbra, 1994; GOMES, Rita Costa - "Virtuosa Benfeitoria". in LANCIANI, Giulia; TAVANI, Giuseppe (org.) - Dicionário da Literatura Medieval..., pp. 681-683; SOARES, Nair de Nazaré Castro - "O Infante D. Pedro e a cultura portuguesa". Biblos. Revista da Faculdade de Letras Universidade de Coimbra (2002), pp. 107-128.

${ }^{14}$ LIVRO DOS OFÍCIOS de Marco Tullio Ciceram, o Qual Tornou em Linguagem o Ifante D. Pedro Duque de Coimbra. Ed. Joseph M. Piel. Coimbra: Universidade de Coimbra, 1948. Ver ainda: CALADO, Adelino de Almeida - "A data da tradução do De Officiis pelo Infante D. Pedro". Revista da Universidade de Aveiro vol.12, p. 198. Para além das obras citadas, consta que o Infante traduziu o De re 
da intervenção epistolar do Infante, a Carta de Bruges, escrita durante a sua passagem pela Flandres, oferece indícios da sua actuação na corte portuguesa. No início da carta o Infante informa a origem da fonte, ou seja, um pedido enviado por D. Duarte, indicando também que a prática de dar conselhos ao irmão era anterior à escrita da epístola ${ }^{15}$. A carta mostra a habilidade político-administrativa de D. Pedro e demarca a sua actividade como conselheiro, o que permitiu que fosse visto como um representante mais qualificado deste pré-renascimento cultural em Portugal ${ }^{16}$. Observa-se que a produção das obras se insere num período de quinze anos (1418-1433) e auxilia-nos na inserção histórica do Infante no contexto anterior e subsequente ao casamento. Destarte, tal como Baquero Moreno, reafirma-se que são escassas as informações sobre a instrução recebida e as experiências vivenciadas entre 1392 e 1415 - ano do nascimento e da conquista de Ceuta, respectivamente -, e mesmo acerca do período que vai até 1438 início da regência de D. Pedro em Portugal ${ }^{17}$.

É ponto comum na historiografia portuguesa, sob o peso das palavras de Oliveira Martins em Os Filhos de D. João I, a defesa de que a primeira metade do século XV foi marcada pela actuação ímpar dos ínclitos infantes de Avis. Nesse quadro laudatório, os casamentos são pouco explorados, com exceção do enlace de D. Isabel, porém permitem-nos observar a política matrimonial de D. João I.

O novo rei português, ainda na posição de Mestre de Avis, fora pai duas vezes, Afonso (c. 1380) e Beatriz (c. 1382), sendo essa descendência ilegítima usada como base para o alargamento da política matrimonial. Nesses anos de afirmação dinástica e ainda sem contar com filhos da rainha D. Filipa em idade nubente, o novo monarca estabeleceu

militari de Vegécio e o De regimine principum de Egídio Romano. D. Pedro atuou ainda como promotor de traduções, tendo encomendado, por exemplo, o Panegírico de Trajano, escrito por Plínio, e o De ingenuis moribus et liberalibus studiis, de Pedro Vergério, ao amigo Dr. Vasco Fernandes de Lucena. Veja-se PINHO, Sebastião Tavares de - "O Infante D. Pedro e a "Escola" de tradutores da Corte de Avis". Actas do Congresso Comemorativo do $6^{\circ}$ Centenário da morte do Infante D. Pedro. Biblos. Revista da Faculdade de Letras - Universidade de Coimbra (1993), pp. 140-148.

${ }^{15}$ D. DUARTE - Livro dos Conselhos Del-Rey D. Duarte. (Livro da Cartuxa). Edição diplomática. Ed. João José Aves Dias. Lisboa: Estampa, 1982, doc. 4, p. 27. "Per vos me foy mandado em hu uosso regymento que despois que fose em esta terra uos fizesse hu escrito d aujsamento tal como o outro que me vos destes".

${ }^{16}$ GODINHO, Vitorino Magalhães - Portugal: a emergência de uma Nação. Lisboa: Edições Colibri, 2004 , p. 76.

${ }^{17}$ MORENO, Humberto Carlos Baquero - "O Infante D. Pedro e o ducado de Coimbra". in $O$ Infante D. Pedro, Duque de Coimbra..., p. 25. 
uma estratégia familiar capaz de promover um fortalecimento interno - casamento de Afonso -, e uma ampliação das relações externas - consórcio de Beatriz ${ }^{18}$.

D. João e D. Filipa tiveram oito filhos, dos quais dois faleceram. Dos seis infantes, apenas dois não casaram, D. Henrique e D. Fernando, mesmo tendo existido oportunidades nesse sentido. O primeiro a casar-se foi o penúltimo filho, o infante D. João, em novembro de $1424{ }^{19}$, matrimónio que uniu o infante à sua sobrinha, única filha do conde de Barcelos, D. Isabel. No entanto, tal enlace, somado ao de D. Afonso com a filha do Condestável, representa uma tendência secundária das uniões estabelecidas pelos filhos de D. João, visto que de oito filhos (legítimos e bastardos), quatro casaram fora de Portugal. A partir das fontes acerca das negociações matrimoniais de D. Afonso, D. Beatriz e do infante D. João, pode-se entrever que estas transações não conheceram delongas, sendo o casamento da infanta com o conde de Arundel o que mais se protelou. A constatação reitera-se na observação das negociações que envolveram os matrimónios de D. Duarte, D. Pedro e D. Isabel, pois este segundo conjunto de casamentos reafirma a tendência de que a procura de um marido ou de uma esposa por um príncipe era um processo longo e complexo ${ }^{20}$.

O estabelecimento de dois conjuntos de casamentos - sendo o primeiro representado por D. Afonso, D. Beatriz e D. João, e o segundo por D. Duarte, D. Pedro e D. Isabel permite ainda que se delimitem distinções entre as consequências de cada um dos grupos de matrimónios para a dinastia de Avis. Acredita-se que ambos reforçaram os laços avisinos dentro e fora de Portugal, contudo também refletem momentos diferentes do reinado de D. João I. Os primeiros ocorreram em um período de busca de afirmação e legitimação dinástica - para o qual a aliança do rei com os Lancaster (1387) já tinha

\footnotetext{
${ }^{18}$ LIMA, Douglas Mota Xavier de - "A política matrimonial de D. João I: um instrumento de afirmação dinástica. Portugal, 1387-1430”, Roda da Fortuna, Revista eletrônica sobre Antiguidade e Medievo, vol. 3, 2 (2014), pp. 193-195. Especificamente sobre o casamento de D. Beatriz, ver: SILVA, Manuela Santos - "O casamento de D. Beatriz (filha natural de D. João I) com Thomas Fitzalan (Conde de Arundel) paradigma documental da negociação de uma aliança”. in FARIA A. L.; BRAGA I. D. (org.) Problematizar a História. Estudos de História Moderna em homenagem à Maria do Rosário Themudo Barata. Lisboa: Caleidoscópio, 2007, pp. 77-91.

19 SOUSA, D. António Caetano de - Provas da História Genealógica da Casa Real Portuguesa. Nova edição revista por Manuel Lopes de Almeida e César Pegado. Coimbra: Livraria Atlântida, 1947, Tomo I, vol. III, pp. 103-104; 182-184 e 187-188; SERRÃO, Joaquim Veríssimo - “João, Infante”. in SERRÃO, Joel (dir.) - Dicionário de História de Portugal. Lisboa: Iniciativas Editoriais, 1975, pp. 604-605.

${ }^{20}$ LIMA, Douglas Mota Xavier de - O Infante D. Pedro e as Alianças externas de Portugal (1425-1449). Niterói: Universidade Federal Fluminense, 2012, Dissertação de Mestrado, pp. 98-119.
} 
contribuído -, com os problemas internos apresentando-se como difíceis obstáculos, e o segundo conjunto de consórcios deu-se num contexto de consolidação e ampliação das alianças externas existentes até então.

Assim, é importante notar que os quatro casamentos dos filhos legítimos de D. João e Filipa ocorreram nos anos de 1420. Chama ainda mais atenção o facto de três casamentos terem ocorrido entre setembro de 1428 e janeiro de 1430. Destes, o enlace do herdeiro (1428) foi investigado no citado estudo de Dias Dinis, no qual se expõe a importância do matrimónio para as relações ibéricas do período. O principal consórcio foi o de D. Isabel (1430) com o duque da Borgonha, que consolidou a presença portuguesa no norte europeu. E o casamento de D. Pedro? Tal como outros aspectos da vida do duque de Coimbra, o enlace mostra-se um obscuro, porém crucial, momento na trajetória biográfica do viajante das Sete Partidas.

Portanto, para finalizar as considerações sobre a política matrimonial de D. João I, afirmamos que os casamentos dos anos de 1420 foram reflexo de uma nova etapa da diplomacia portuguesa. A posição interna de Avis já estava estabilizada e a aliança inglesa estruturada e reafirmada com o consórcio de Beatriz. A conquista de Ceuta (1415) tinha permitido a construção de uma imagem do reino e da dinastia reinante articulada com os valores cristãos e com a defesa da Cristandade, elementos que favoreciam a honra da família real avisina no cenário das casas principescas. Por fim, os casamentos do período demonstram o esforço do reino de Portugal em consolidar-se no cenário político ibérico, mormente através da aliança com Aragão e, ultrapassando este quadro diplomático tradicional, enrijecer os laços com o mar do Norte, por meio do enlace com o ducado de Borgonha.

A fim de organizar a exposição sobre o enlace do Infante, orientaremos a discussão de acordo com os seguintes tópicos: as anteriores propostas de casamento; o momento do enlace, como etapa da vida de D. Pedro; a escolha da noiva, D. Isabel de Urgel; o casamento e as suas consequências. 
As primeiras menções sobre propostas de aliança matrimonial envolvendo D. Pedro aparecem em dois documentos do rei D. Martin de Aragão, datados de abril de 1410, no qual o monarca expõe o interesse de casar a infanta D. Leonor de Urgel, ou com D. Duarte ou com o Infante ${ }^{21}$. Novas alusões surgem alguns anos depois, de acordo com o texto da Crónica da Tomada de Ceuta, ao descrever o envio dos embaixadores portugueses à Sicília. Esta missão teve como pretexto tratar do matrimónio proposto pela rainha viúva, D. Branca, com o infante D. Duarte, ou com D. Pedro. De acordo com Zurara, após descartarem o avanço das negociações com o príncipe herdeiro, os enviados portugueses afirmaram que D. João I via com prazer que o casamento da rainha se concretizasse com o secundogénito ${ }^{22}$. Contudo, ainda segundo o cronista, a rainha ficou "mui pouco contente" com a posição da embaixada, visto que "lhe parecia que seu estado receberia abatimento, mandando ela, primeiramente, tratar casamento com o infante D. Duarte, que era herdeiro do reino, e tornar a casar com o infante D. Pedro que era sojeito a seu irmão por razão de sua primeira nascença"23.

A descrição cronística dessa missão diplomática é oscilante nas informações oferecidas, pois afirma ser D. Pedro o noivo buscado pela rainha da Sicília (Capítulo XV), depois indica que D. Duarte era o objeto da negociação e que o Infante era uma proposta secundária no consórcio $^{24}$ (Capítulo XVI), e finaliza com a menção do descontentamento da rainha perante a proposta de casamento com o secundogénito português $^{25}$.

\footnotetext{
${ }^{21}$ DINIS, António Joaquim Dias - "À volta do casamento do infante D. Duarte"..., doc. 2 e 3, pp. 42-43. Os referidos documentos encontram-se publicados ainda na MONUMENTA HENRICINA. Ed. António Joaquim Dias Dinis. Coimbra: Comissão Executiva das Comemorações do V Centenário da morte do Infante D. Henrique, 1960-1974, Vol. I, doc. 141 e 142, pp. 326-328.

${ }^{22}$ ZURARA Gomes Eanes de - Crónica da Tomada de Ceuta, Capítulo XVI, p. 81.

${ }^{23}$ ZURARA Gomes Eanes de - Crónica da Tomada de Ceuta, Capítulo XVI, p. 82.

${ }^{24}$ A partir da crónica, é possível inferir que a proposta de envolver D. Pedro na negociação foi de D. João I, não da rainha da Sicília - como o próprio Zurara afirma no capítulo anterior -, visto que o rei formou a embaixada como uma forma de dissimulação pois sabia os problemas implicados no estatuto do Infante ("A qual cousa eu sei pelo requerimento que me ela enviou fazer que me prouvesse de casar meu filho o Infante Dom Pedro, a qual cousa eu sei bem que certo ela não há-de fazer. Empero a aproveitará muito semelhante cometimento porquanto meus embaixadores terão azo de ir e vir por acerca daquela cidade [Ceuta], onde poderão devisar todo o que lhe por mim for mandado". ZURARA Gomes Eanes de Crónica da Tomada de Ceuta..., Capítulo XV, p. 79).

${ }^{25}$ Trata-se de D. Branca I de Navarra, esposa de Martin I, o Jovem, rei da Sícília e herdeiro de Aragão. Após a morte deste, em 1410, Branca permaneceu à frente do reino da Sicília até 1415. Sobre a rainha, ver: FODALE, Salvatore - "Blanca de Navarra y el gobierno de Sicilia". Principe de Viana 60 (1999), pp. 311-322.
} 
É possível inferir que alguma proposta de casamento possa ter surgido na cidade de Viena em inícios de 1426, visto que, de acordo com Albert Starzer, o baile oferecido ao Infante, na chamada casa de Praga, foi largamente concorrido pelas damas da cidade ${ }^{26}$. Contudo, com a exceção desta inferência a partir do estudo de Domingos Maurício dos Santos, não há outra informação que envolva o tema do casamento durante a viagem.

Sabe-se que os casamentos entre famílias régias eram, sobretudo, um acto político, comumente lento na condução das negociações, o que se dava em virtude das estratégias políticas das casas reais e das disponibilidades de noivos e noivas das mesmas. Tais dificuldades e frequentes mudanças de políticas matrimoniais possibilitavam vários casos de nobres que não contraíam casamento, sendo emblemático o exemplo do infante D. Henrique. Todavia, aos trinta e seis anos, D. Pedro casou-se.

Tal aspecto, a idade do Infante, chama a atenção e demanda uma reflexão pormenorizada, a qual não aparece valorizada na bibliografia que trata do casamento dos infantes avisinos. Perspectivas gerais sobre as idades na Europa do período, trazem a seguinte indicação:

Tabela 1. Idades segundo J. C. Russell (500-1500) $)^{27}$

\begin{tabular}{|c|c|}
\hline Infância I & $0-7$ anos \\
\hline Infância II & $7-14$ anos \\
\hline Juventude & $14-20$ anos \\
\hline Idade adulta & $20-40$ anos \\
\hline Maturidade & $40-60$ anos \\
\hline Senilidade & +60 anos \\
\hline
\end{tabular}

Segundo este esquema, D. Pedro aparece na "idade adulta" quando resolveu casar (trinta e seis anos), aliás, próximo da "maturidade". No entanto, para não fundamentar uma

\footnotetext{
26 STARZER, Albert - Geschichte der Stadt Wien. III Band, p. 680, citado a partir de SANTOS, Domingos Maurício Gomes dos - "O Infante D. Pedro na Áustria-Hungria". Brotéria. Revista Contemporânea de Cultura. Tomo LXVIII, Lisboa (1959), p. 20.

27 RUSSELL, J. C - "Population in Europe, 500-1500". in CIPOLLA, Carlo M. (ed.) - The Fontana Economic History of Europe. Vol. I, The Middle Ages. London: Collins-Fontana Books, 1978, p. 42, citado a partir de MARQUES, António H. de Oliveira - Portugal na crise dos séculos XIV e XV. Lisboa: Presença, 1987, p. 22.
} 
posição apenas em perspectivas genéricas, espacial e temporalmente, veja-se a seguinte consideração de D. Duarte acerca das idades:

Tabela 2. As idades segundo D. Duarte ${ }^{28}$

\begin{tabular}{|c|c|c|c|}
\hline $0-7$ anos & $1^{\mathrm{a}}$ idade & $1^{\mathrm{a}}$ dentição & Infância \\
\hline $7-14$ anos & $2^{\mathrm{a}}$ idade & Maturação sexual & Puerícia \\
\hline $14-21$ anos & $3^{\mathrm{a}}$ idade & Conclusão do crescimento & Adolescência \\
\hline $21-28$ anos & $4^{\mathrm{a}}$ idade & Maturidade física & Mancebia \\
\hline $28-35$ anos & $5^{\mathrm{a}}$ idade & Maturidade intelectual & Mancebia \\
\hline $35-42$ anos & $6^{\mathrm{a}}$ idade & Início da decadência & Mancebia \\
\hline $42-49$ anos & $7^{\mathrm{a}}$ idade & Decadência & Mancebia \\
\hline $49-56$ anos & $8^{\mathrm{a}}$ idade & Início da decrepitude & Velhice \\
\hline
\end{tabular}

Estes apontamentos foram feitos pelo próprio irmão de D. Pedro que, ao estabelecer esta teoria das idades, permite que a decisão do casamento seja redirecionada para o "início da decadência" da vida do homem. De qualquer forma, pelos elementos já levantados, mostrase nítido que o matrimónio do duque de Coimbra foi decidido numa idade avançada da sua vida - facto que também ocorreu com D. Duarte, que casou aos trinta e sete anos. Não obstante, antes de finalizar esta observação e a fim de oferecer ainda mais elementos que corroborem a posição tomada, recupera-se um novo levantamento sobre o tema, este feito por Armindo de Sousa abordando a média de vida dos reis, rainhas e príncipes:

Tabela 3. Idades e médias de vida $(\mathbf{1 3 0 0 - 1 5 0 0})^{29}$

\begin{tabular}{|c|c|c|c|}
\hline Anos vividos & Sexo masculino & Sexo feminino & Total \\
\hline $10-19$ & 2 & 0 & 2 \\
$20-29$ & 0 & 3 & 3 \\
$30-39$ & 2 & 6 & 8 \\
$40-49$ & 9 & 1 & 10 \\
$50-59$ & 3 & 2 & 5 \\
$59-69$ & 4 & 3 & 7 \\
$70-79$ & 1 & 1 & 2 \\
$80-89$ & 1 & 0 & 1 \\
\hline Totais & 22 & 16 & 38 \\
\hline Média de vida & 49,5 anos & 44,3 anos & \\
\hline
\end{tabular}

28 SOUSA, Armindo de - "Condicionamentos básicos". in MATTOSO, José (dir.) - A Monarquia Feudal. História de Portugal. Vol. II. Lisboa: Estampa, 1993, p. 358. O quadro foi desenvolvido por Sousa a partir do capítulo1 do Leal Conselheiro, escrito por D. Duarte.

${ }^{29}$ SOUSA, Armindo de - "Condicionamentos básicos”..., p. 359. 
Levando em consideração tais elementos, defendemos que a decisão de D. Pedro em assumir o casamento expressa uma cautela significativa, a qual somente foi rompida quando o irmão e herdeiro D. Duarte finalizou a sua negociação matrimonial ${ }^{30}$. Naquele contexto, qualquer imprevisto que ocorresse com o príncipe herdeiro, o Infante seria o próximo na escala de sucessão e, assim, um enlace prévio poderia prejudicá-lo na nova posição. Numa sociedade em que a esperança de vida era baixa, que diversos imprevistos e guerras ceifavam vidas de nobres ou camponeses, e que a peste e a fome eram um espectro presente e real ${ }^{31}$, não é absurdo acreditar que D. Pedro pudesse ter expectativas de assumir o trono.

As decisões do Infante parecem confirmar a hipótese de tal cautela. D. Duarte casou-se a 22 de setembro de 1428, e o duque de Coimbra finalizou o seu contrato de casamento nove dias antes, a 13 de setembro. A sincronização de datas é reveladora e não parece meramente ocasional. Estas observações não têm o interesse de reforçar uma ideia equivocada que apresenta D. Pedro como um homem ávido pelo poder, ambicioso e com a expectativa de que o irmão mais velho morresse o quanto antes para que pudesse assumir o trono. Pelo contrário, buscamos ressaltar que a sua postura após o retorno das viagens e, principalmente, após o casamento de D. Duarte e o nascimento de D. Afonso $\mathrm{V}$, mostram um Infante mais preocupado com a Casa de Coimbra, sem que isso o impedisse de continuar atuando na administração régia, acções essas que indicam a reorientação da nova posição social e potencial de D. Pedro.

Dito isso, segue-se recuperando outro problema relativo ao casamento: a noiva. A escolhida do Infante foi D. Isabel, representante de um importante ramo da nobreza aragonesa, a família Urgel. O "problema” é que esta princesa era filha do duque de Urgel, D. Jaime, derrotado e encarcerado por D. Fernando de Antequera, pai de D. Alfonso V, rei de Aragão, e de D. Leonor, esposa de D. Duarte e futura rainha de

\footnotetext{
${ }^{30}$ Tal proposta foi esboçada em minha monografia (LIMA, Douglas Mota Xavier de - Um ilustre viajante português do século XV: as viagens do Infante D. Pedro de Portugal (1425-1428). Niterói: Universidade Federal Fluminense, 2009, pp. 96-97 e 106-107), e defendida recentemente na Dissertação de Mestrado (O Infante D. Pedro e as Alianças externas de Portugal (1425-1449)...). Noutra perspectiva, a ideia de que o casamento de D. Duarte motivou a escolha do Infante, pode ser verificada em: SERRÃO, Joaquim Veríssimo - História de Portugal. Volume II. Formação do Estado Moderno (1415-1495). Lisboa: Verbo, $2^{a}$ edição, 1978, p. 33 (“O consórcio de D. Duarte, em vésperas de celebrar-se, acordou em D. Pedro o desejo de se matrimoniar").

${ }^{31}$ A peste ceifou, por exemplo, a vida de D. Duarte em 9 de setembro de 1438, à época com 47 anos.
} 
Portugal $^{32}$. Eis o pomo da discórdia histórica e, principalmente, historiográfica, que vem suscitando diversas indagações: tal escolha foi um acto isolado de D. Pedro ou insere-se na política matrimonial de D. João I? A opção foi precipitada e equivocada, com consequências negativas, ou, pelo contrário, a posição foi acertada e favoreceu a causa portuguesa?

Como exemplo das leituras historiográficas, temos a posição de Luís Miguel Duarte de que a escolha foi precipitada e incoerente:
"O que quero dizer é que Isabel, a esposa do infante D. Pedro, era inimiga jurada dos Infantes de Aragão e, portanto de Leonor, a mulher de D. Duarte; fora o pai de Leonor a derrotar e a sepultar numa fortaleza o pai de Isabel e todas as ambições e o passado da casa de Urgel. Parece uma estratégia matrimonial bizarra" 33 .

E de António Joaquim Dias Dinis:

\begin{abstract}
"Dos documentos conhecidos não consta qualquer interferência do soberano aragonês ou de sua esposa nesse matrimônio. Sabemo-los, porém, empenhados em arrumar, em casamento condigno, as filhas do detido conde de Urgel. De sorte que, eles não atentaram nos inconvenientes que podiam advir ao trono de Aragão do enlace matrimonial de D. Isabel de Urgel com o infante D. Pedro de Portugal. Afigurou-se-lhes até, porventura, este outro matrimônio reforço da aliança efetuada entre os dois reinos pelo recente casamento de D. Leonor com o infante português D. Duarte" ${ }^{34}$.
\end{abstract}

\footnotetext{
${ }^{32}$ Após o Compromisso de Caspe (5 de setembro de 1412) o conde D. Jaime de Urgel refugiou-se no castelo de Balanguer, onde foi cercado no mês de outubro. Desse momento em diante foi despojado dos títulos e bens, e aprisionado na povoação de Urueña, em Castela. A esposa e as filhas foram levadas para o mosteiro de Sixena, no reino castelhano, ficando sob a guarda de D. Leonor de Albuquerque, esposa de D. Fernando e rainha de Aragão (RODRIGUES, Ana Maria S. A. - "D. Leonor, Infanta de Aragão, Rainha de Portugal: linhagem, gênero e poder na Península Ibérica do século XV". in Raízes medievais do Brasil moderno - Actas. Lisboa: Academia Portuguesa de História, 2008. pp. 217-218).

${ }^{33}$ DUARTE, Luís Miguel - D. Duarte. (1391-1438). Lisboa: Círculo de Leitores, Temas e Debates, 2007, p. 170.

${ }^{34}$ DINIS, António Joaquim Dias - "À volta do casamento do infante D. Duarte”..., p. 36.
} 
D. Isabel era filha do ex-conde de Urgel. O Infante sabia dessa circunstância, fora informado do enlace do irmão ainda nas terras do Império, e mesmo assim escolheu a infanta de Urgel como esposa: porquê? Visando oferecer possíveis respostas para tantas indagações, a primeira constatação é de que o enlace de D. Pedro não foi conduzido pelo rei de Portugal. A negação é adotada aqui tanto por não existir nenhum vestígio de que D. João I se tenha envolvido na negociação do casamento - cartas ao Infante, embaixadores à Aragão sobre o tema, etc. -, como por haver indícios de que o rei português não ofereceu os devidos auxílios para a chegada de D. Isabel a Portugal $^{35}$. Assim, seria a decisão um acto isolado de D. Pedro?

Pergunta complexa que tem respostas possibilitadas pela observação da etapa ibérica da viagem. No entanto, este caminho depara-se com oposições na historiografia. Escolhendo algumas obras como exemplo, vemos que existem posições completamente contrastantes, umas defendendo que a escolha foi exclusivamente de D. Pedro ${ }^{36}$, outras que foi uma estratégia de Álvaro de Luna contra os Trastâmaras ${ }^{37}$, e ainda a de que se tratou de um plano do Magnânimo para se fortalecer internamente ${ }^{38}$. Não seria satisfatório descartar uma alternativa, mas estamos inclinados a dar menor importância à primeira, em virtude dos vestígios deixados pela viagem. Desta forma, restam dois

\footnotetext{
${ }^{35} \mathrm{O}$ contrato matrimonial de D. Pedro foi celebrado em 13 de setembro de 1428, dando o Infante por arras à D. Isabel 6000 florins de ouro de Aragão, garantidos pelos seus castelos de Montemor-o-Velho e Tentúgal. O dote da noiva foi estabelecido em 40900 florins de ouro, fidelizados pelo castelo de Alcolea. O contrato foi confirmado por D. João I e D. Duarte somente em março de 1429, e ainda no mês de maio, D. Isabel permanecia em Aragão. MONUMENTA HENRICINA..., Vol. III, doc. 122, pp. 244-250; doc. 133, pp. 284-285. Este documento indica que D. Alfonso de Aragão ofereceu 1000 florins de ouro para subsidiar a viagem de D. Isabel para Portugal.

36 "Num exemplo pouco vulgar para a época, escolheu ele [D. Pedro] mesmo a sua mulher" (MARQUES, Alfredo Pinheiro - Vida e Obra do Infante D. Pedro..., p. 12).

37 "E aquele desagrado de Luna [com a aliança luso-aragonesa através do casamento de D. Duarte] deve ter sido confirmado na longa conferência de Aranda de Duero com o infante D. Pedro de Portugal, que, por isso, ali ficou habilitado a declarar, nas suas procurações de setembro seguinte, datadas de Valhadolide e de Zamora, o nome de sua noiva, D. Isabel de Urgel" (DINIS, Antonio Joaquim Dias - "À volta do casamento de D. Duarte"..., pp. 37-38).

38 "Estou convicto de que este monarca [D. Afonso V] concebeu um plano. Na sequência da tumultuosa designação do seu pai, Fernando de Antequera, como rei de Aragão (...), ficaram muitas feridas abertas. As piores, provavelmente, na Catalunha, devido à revolta e à derrota do Conde de Urgel. (...) $\mathrm{O}$ casamento das filhas do conde D. Jaime podia ser, neste contexto, um contributo decisivo para virar a página. E de repente desembarca-lhe em Valência o infante D. Pedro, prestigiado em toda a Europa, filho segundo do rei de Portugal, irmão do príncipe D. Duarte que, dali a algumas semanas, se casaria com a sua (dele, Afonso V) irmã Leonor. Se o ligasse a uma filha do conde de Urgel, Afonso V começava a resolver um dos seus maiores problemas e aproximava as famílias rivais, a sua e a de Urgel, casando duas donzelas 'adversárias' com dois irmãos” (DUARTE, Luis Miguel - D. Duarte. (1391-1438)..., p. 171).
} 
caminhos interpretativos completamente opostos, e não deixaremos de tomar posição acerca da querela.

Durante as festas de Valladolid, celebração da despedida da infanta D. Leonor, o Condestável de Castela e o próprio rei D. Juan II conduziram as festividades, fazendo com que o casamento da infanta aragonesa fosse assumido pelo poder castelhano e, consequentemente, contribuísse para a paz entre este reino e Portugal ${ }^{39}$. Tal leitura é ainda corroborada pela carta de D. Duarte a D. Pedro, no qual o herdeiro reclama de D. Leonor não ter sido acompanhada pelos irmãos, D. Juan e D. Enrique, durante a saída de Castela ${ }^{40}$. Segundo os argumentos de Luís Miguel Duarte, acredita-se que esta mudança ocorrida na celebração de Valladolid fez com que o casamento do herdeiro português perdesse parte de sua potencialidade na aliança com Aragão, favorecendo, por outro lado, a relação luso-castelhana. Dito isso, e sendo presumível que o contacto entre Álvaro de Luna e D. Pedro tenha ocorrido em Aranda, se porventura o consórcio do Infante foi tratado nesse encontro, Luna pode ter procurado a associação do duque de Coimbra à Casa de Urgel para, com isso, enfraquecer a posição dos Infantes de Aragão ${ }^{41}$.

A hipótese é plausível e, comumente, a aproximação entre tais personagens nos anos da regência (1438-1448) tende a fundamentar esta posição ${ }^{42}$. Contudo, adotá-la seria aceitar que D. Pedro discordava, ou passou a discordar por influência de D. Álvaro, da opção matrimonial do irmão D. Duarte, e isto não parece ter fundamentação sólida. O Infante estava ciente das negociações luso-aragonesas desde 1422 e não há registo de que se tenha oposto a $\mathrm{D}$. Leonor antes do período da regência ${ }^{43}$.

\footnotetext{
${ }^{39}$ DUARTE, Luis Miguel - D. Duarte. (1391-1438) ..., pp. 150-154.

${ }^{40}$ D. DUARTE - Livro dos Conselhos Del-Rey D. Duarte..., doc. 7, p. 50.

41 "Para tanto, o condestável terá favorecido a aproximação entre o Infante e a Casa de Urgel, pois D. Álvaro de Luna sabia que teria um ótimo aliado se D. Pedro casasse com uma das filhas daquele Conde". ARAÚJO, Julieta - Portugal e Castela na Idade Média. Lisboa: Edições Colibri, 2009, p. 52.

42 Julieta Araújo defende, por exemplo, que a amizade começou nessa visita de D. Pedro: "A amizade entre D. Pedro e o condestável de Castela seria, como dissemos, duradoura e muito terá contribuído para o resultado final do casamento do Infante". ARAÚJO, Julieta - Portugal e Castela na Idade Média..., p. 53.

${ }^{43}$ Ressalta-se que na carta que D. Duarte enviou a D. Pedro, exortando-o a não permanecer descontente, em nenhum momento o herdeiro critica o irmão pela opção matrimonial. (D. DUARTE - Livro dos Conselhos Del-Rey D. Duarte..., doc. 7, pp. 50-55). Além disso, o Infante atuou destacadamente durante a celebração do casamento de D. Duarte, sempre próximo de D. Leonor. D. Pedro aparece na corte régia durante as festas de despedida da infanta D. Isabel, em virtude do casamento com o duque da Borgonha,
} 
Destarte, permanece a perspectiva de que o consórcio foi influenciado pelo rei de Aragão. Esta hipótese parece-nos mais concreta, e os vestígios da viagem também corroboram esse caminho interpretativo. Alfonso $\mathrm{V}$ preocupou-se em avisar o Infante da união de D. Duarte com D. Leonor (agosto de 1427) ${ }^{44}$, recebeu o viajante com todas as honras e exaltando os vínculos de parentesco entre os mesmos (Julho de 1428) ${ }^{45}$, e, principalmente, foi com este rei que Aires Gomes da Silva ficou de negociar o casamento de D. Pedro (agosto de 1428) ${ }^{46}$. Recupera-se a sequência cronológica dos factos: o duque de Coimbra foi festejado em Valência, e nesse contexto decidiu iniciar a procura de uma esposa; apenas cinco dias depois foi assinada uma procuração da parte de Isabel de Urgel para a negociação do contrato de casamento com D. Pedro; ao partir de Aragão, o Infante deixou um procurador para tratar do assunto com Alfonso V, sem indicar previamente com quem se interessava casar; após um primeiro encontro com D. Juan II (e D. Álvaro de Luna?), foi ao encontro do rei de Navarra, irmão de Alfonso V e D. Leonor, em Peñafiel, e voltou à presença do rei de Castela durante alguns dias; por fim, em Valladolid, afirmou que o casamento deveria ser tratado com D. Isabel de Urgel.

Nesta exposição fica claro que a paragem em Aragão demarca o início da negociação de casamento, para a qual Alfonso V contribuiu e deu assistência ao procurador do Infante. Por mais que os documentos provenientes de D. Pedro não indiquem quem deveria ser a noiva, antes do Infante sair de Aragão a transação com os procuradores de D. Isabel já havia começado. A estadia com o rei de Castela, entrecortada com a visita ao outro infante de Aragão, D. Juan, pode ter influenciado na decisão por Isabel, mas isso não quer dizer que tal escolha representasse uma oposição à causa aragonesa. Afinal, o casamento de D. Pedro com a infanta de Urgel era bom tanto para D. Álvaro de Luna quanto para os Infantes de Aragão. No entanto, reafirma-se, a opção favoreceu, ao menos naquela circunstância, a posição de D. Alfonso V.

aparição que se deu ao lado da esposa e da cunhada. Tais elementos não permitem descartar algum desentendimento entre Pedro e Leonor, mas também possibilitam que não se adote a oposição entre os mesmos.

${ }^{44}$ MONUMENTA HENRICINA..., Vol. III, doc. 80, p. 163.

${ }^{45}$ MONUMENTA HENRICINA..., Vol. III, doc. 106, pp. 218-219.

${ }^{46}$ MONUMENTA HENRICINA..., Vol. III, doc. 113, pp. 228-230; doc. 120, pp. 239-240; doc. 121, pp. 240-244. 
A região da Catalunha, marcada pelos apoiantes do Conde de Urgel, oferecia dificuldades ao rei aragonês que, no período, enfrentava ainda problemas no Mediterrâneo e em Castela com o enfraquecimento da posição política dos irmãos. Soma-se ainda o facto de a constante ausência de D. Alfonso das terras aragonesas, instalando-se, frequentemente, em Nápoles, o que permitiu que o seu governo interno fosse prejudicado ${ }^{47}$. Após a morte da condessa de Urgel (1424), coube a Alfonso V prover e casar as filhas de Jaime, e por tal incumbência consorciou D. Isabel com D. Pedro em $1428^{48}$. A priori, o casamento representou um reforço interno e externo da posição do Magnânimo, favorecendo um dos ramos da nobreza opositora à sua causa, principalmente na região da Catalunha, e ainda fortaleceu e ampliou as relações familiares com Avis. Esta escolha interpretativa talvez fique mais clara ao refletir-se acerca da outra indagação feita anteriormente: a opção do casamento foi precipitada e equivocada, com consequências negativas, ou, pelo contrário, a posição foi acertada e favoreceu a causa portuguesa?

Frente a este problema, adotaremos a mesma perspectiva assumida quanto à escolha da esposa do Infante. Desta forma, percebe-se que as duas propostas presentes na pergunta têm fundamentos e cabe, assim, decidir pela que acreditamos ser mais coerente. Para tal, estabelecemos um critério de análise: observar o contexto anterior e posterior ao casamento de D. Pedro. A fim de oferecer uma precisão cronológica para a escolha, definimos o período de uma década, 1425-1435, respectivamente, o ano da partida do Infante e meados do reinado de D. Duarte.

Ao longo dos anos de 1420 - circunstância que se manteria, ao menos, até a morte de D. João I (1433) - a situação portuguesa na Península Ibérica viu-se fortalecida. Nesse sentido contribuíram a ratificação do tratado de Ayllon, em 1423, garantindo a manutenção da paz luso-castelhana, a qual seria reafirmada em 1431; a longa negociação do casamento de D. Duarte e D. Leonor de Aragão (1422-1428); o

\footnotetext{
47 OCHOA BRUN, Miguel Angel - Historia de la Diplomacia Española. Vol. 2. Madrid: Biblioteca Diplomática Española, 2003, p. 183 e pp. 189-191.

${ }^{48}$ MENÉNDEZ PIDAL, Ramón - "El compromisso de Caspe, autodeterminación de un pueblo (14101412)". in MENÉNDEZ PIDAL, Ramón (dir.) - Historia de España. Tomo XV. Los Trástamaras de Castilla y Aragón en el siglo XV. Madrid: Espasa-Calpe, 1964, p. CXLIII.
} 
estabelecimento de alianças com D. Alfonso V e D. Juan, rei de Navarra; e a busca da mediação no conflito entre os Infantes de Aragão e Castela ${ }^{49}$.

Para além da pacificação das relações luso-castelhanas - um objetivo buscado incisivamente por D. João I -, destaca-se o interesse joanino na relação com Aragão. Mais do que um reino capaz de balancear as relações políticas na península, principalmente no contexto de afirmação avisina, ou um pilar da política externa portuguesa, Aragão possibilitava a ampliação das relações económicas de Portugal com diferentes praças mediterrâneas ${ }^{50}$. Ultrapassando as importantes relações económicas, D. João I buscou uma aliança política com o reino de D. Alfonso V, a qual se fundamentaria num forte elo: o casamento de seu herdeiro, D. Duarte. Enfatizo: a iniciativa foi do rei de Portugal.

Este conjunto de indicações permite afirmar que na década de 1420 a política diplomática de D. João privilegiava as relações luso-aragonesas. Por outro lado, também é possível dizer que a coroa de Aragão dava muita importância a tal vínculo com Portugal ${ }^{51}$. Logo, por mais que se defenda que o casamento de D. Pedro não foi traçado por D. João I, admite-se que o consórcio estava inserido, de forma coerente ${ }^{52}$, no conjunto da política diplomática avisina no período. Descarta-se, assim, apenas a opção de equívoco no enlace do Infante, visto que, pelo tempo de negociação (julhosetembro), parece que o contrato matrimonial foi de facto um tanto acelerado, o que não indica necessariamente um problema.

Da primeira parte da indagação resta refletir sobre as consequências negativas do casamento. Contudo, levando em consideração os elementos já expostos, acreditamos

\footnotetext{
49 Sobre o contexto ibérico da década de 1420, ver: SUARÉZ FERNÁNDEZ, Luís - "Los infantes de Aragón y Don Álvaro de Luna". in MENÉNDEZ PIDAL, Ramón (dir.) - Historia de España. Tomo XV. Los Trástamaras..., pp. 69-122; Nobleza y Monarquía. Entendimiento y Rivalidad. El proceso de la construcción de la coronã española. Madrid: La Esfera de los libros, 2005, pp. 179-210.

${ }^{50}$ Veja-se BARATA, Filipe Themudo - Navegação, Comércio e Relações Políticas: os portugueses no Mediterrâneo ocidental (1385-1466). Lisboa: Fundação Calouste Gulbenkian, 1998; FONSECA, Luís Adão da - Os Descobrimentos e a formação do Oceano Atlântico. Século XIV-XVI. Lisboa: Comissão Nacional para as Comemorações dos Descobrimentos portugueses, 1999.

${ }^{51}$ OCHOA BRUN, Miguel Angel - Historia de la Diplomacia Española..., p. 186 ("Los Buenos ofícios y la amistad de Juan I de Portugal eran para don Alfonso una baza de muy grande importancia").

52 Discorda-se, por exemplo, da posição de Luís Miguel Duarte, que classifica o casamento de D. Pedro como "uma estratégia matrimonial bizarra" (DUARTE, Luis Miguel - D. Duarte. (1391-1438)..., p. 170).
} 
que o principal problema relativo a este mote é a questão da interpretação histórica dos factos. Dizemos isto porque não encontramos indícios de que a união de D. Pedro foi negativa para Portugal e para Aragão ${ }^{53}$. Apesar disso, são frequentes as análises que criticam o casamento, tomando como base os acontecimentos posteriores à morte de $\mathrm{D}$. Duarte: o conflito entre o Infante e D. Leonor pela regência (1438-1439); a posição de D. Afonso V [rei português] contra o Duque de Coimbra (1448-1449); a morte de D. Pedro em Alfarrobeira (1449); e mesmo a guerra civil ocorrida na Catalunha (14641466) que teve a participação de D. Pedro, primeiro filho do Infante. Conclui-se, comumente, que o facto de o pai de D. Isabel ter sido derrotado e encarcerado por Fernando de Antequera, pai de D. Leonor, gerou um ódio, uma rivalidade, uma oposição entre as cunhadas que daria o tom das disputas políticas em Portugal nos anos de 1430 e de $1440^{54}$. Deste modo, defendemos que as consequências negativas do casamento são resultado, principalmente, de leituras que explicam o enlace tendo em vista os difíceis acontecimentos posteriores.

Por fim, um outro episódio contribui para a hipótese defendida, e corrobora a escolha cronológica feita para a alínea. Trata-se de um documento de 1435, no qual a rainha de Aragão, D. Maria, propunha que as outras irmãs de D. Isabel de Urgel - a saber, D. Leonor e D. Joana - se casassem em Portugal com os infantes D. Henrique e D. Fernando, que até o momento permaneciam solteiros ${ }^{55}$. Esta carta, endereçada ao Infante, demonstra que em meados da década de 1430, a união Avis-Urgel, estabelecida através de D. Pedro, visava ser ampliada e, mais uma vez, por iniciativa da coroa aragonesa. Portanto, se existiram consequências negativas do casamento do duque de Coimbra com Isabel de Urgel, estas foram posteriores e decorrentes da conjuntura e dos acontecimentos que se seguiram aos finais da década de 1430, logo, não podem ser imputadas à decisão tomada em 1428.

\footnotetext{
${ }^{53}$ No período que estabeleci anteriormente, até 1435.

${ }^{54}$ Não quero com isso desconsiderar a questão, mas são inúmeros os casos históricos em que os algozes tornaram-se aliados, e não objeto de vingança.

${ }^{55}$ MONUMENTA HENRICINA..., Vol. V, doc. 65, pp. 148-149.
} 
No bojo dessas reflexões, concluimos que o consórcio de D. Pedro favoreceu a causa portuguesa perante Aragão. Inseriu-se no conjunto da política externa joanina, a qual tinha como um dos vetores a intervenção no Mediterrâneo e, para tal, a aliança com a monarquia aragonesa era fundamental. Como afirma Adão da Fonseca, os olhos de Portugal estavam postos em duas cidades da Coroa de Aragão, Barcelona e Valência ${ }^{56}$. Interessante e não ocasional que tais cidades foram pontos de paragem da viagem, além de serem localidades marcadas pelo urgelismo.

\section{Referências bibliográficas:}

\section{Fontes}

ÁLVARES, Frei João - Chronica dos feitos, vida, e morte do Iffante Sancto Dom Fernando que morreo em Fez. Ed. António Ribeiro. Lisboa, 1577.

CHRONICA DO CONTESTABRE de Portugal Dom Nuno Alvarez Pereira. Ed. F. França Amado. Coimbra, 1911.

DOM PEDRO, Infante - Livro da Vertuosa Benfeytoria. Ed. Adelino de Almeida Calado. Coimbra: Universidade de Coimbra, 1994.

D. DUARTE - Livro dos Conselhos Del-Rey D. Duarte. (Livro da Cartuxa). Edição diplomática. Ed. João José Aves Dias. Lisboa: Estampa, 1982.

LIVRO DOS OFÍCIOS de Marco Tullio Ciceram, o Qual Tornou em Linguagem o Ifante D. Pedro Duque de Coimbra. Ed. Joseph M. Piel. Coimbra: Universidade de Coimbra, 1948.

LOPES, Fernão - Crónica de D. João I. Segundo o códice ${ }^{\circ} 352$ do Arquivo Nacional da Torre do Tombo. Introdução de Humberto Baquero Moreno. Prefácio de António Sérgio. Vol. 2. Porto: Livraria Civilização, 1983.

\footnotetext{
${ }^{56}$ FONSECA, Luís Adão da. Os Descobrimentos e a formação do Oceano Atlântico, p.60.
} 
MONUMENTA HENRICINA. Ed. António Joaquim Dias Dinis. Coimbra: Comissão Executiva das Comemorações do V Centenário da morte do Infante D. Henrique, 19601974.

PINA, Ruy de - Chrónica de El-Rei D. Affonso V. Biblioteca de Clássicos Portugueses. Introdução de Gabriel Pereira. Lisboa: Escriptorio, 1901, 3v.

PISANO, Mateus de - Livro da Guerra de Ceuta. Ed. Roberto Corrêa Pinto. Lisboa: Academia das Sciências de Lisboa, 1915.

SOUSA, D. António Caetano de - Provas da História Genealógica da Casa Real Portuguesa. Nova edição revista por Manuel Lopes de Almeida e César Pegado. Coimbra: Livraria Atlântida, 1947.

ZURARA Gomes Eanes de - Crónica da Tomada de Ceuta. Ed. Reis Brasil. Mem Martins: Publicações Europa-América, 1992.

ZURARA, Gomes Eanes de - Crónica do Conde Dom Pedro de Menezes. Ed. José Adriano de Freitas Carvalho. Porto: Programa Nacional De Edições Comemorativas dos Descobrimentos Portugueses, 1988.

\section{Estudos}

ARAÚJO, Julieta - Portugal e Castela na Idade Média. Lisboa: Edições Colibri, 2009.

BARATA, Filipe Themudo - Navegação, Comércio e Relações Políticas: os portugueses no Mediterrâneo ocidental (1385-1466). Lisboa: Fundação Calouste Gulbenkian, 1998.

CALADO, Adelino de Almeida - "A data da tradução do De Officiis pelo Infante D. Pedro". Revista da Universidade de Aveiro vol. 12 (1995), pp.187-208. 
DINIS, António Joaquim Dias - “À volta do casamento de D. Duarte. (1409-1428)”. in Separata da Revista Portuguesa de História. Coimbra: Universidade de Coimbra, Tomo XV, 1974, pp. 5-70.

DUARTE, Luís Miguel - D. Duarte. (1391-1438). Lisboa: Círculo de Leitores, Temas e Debates, 2007.

FODALE, Salvatore - "Blanca de Navarra y el gobierno de Sicilia". Principe de Viana 60 (1999), pp. 311-322.

FONSECA, Luís Adão da - Os descobrimentos e a formação do Oceano Atlântico. Século XIV-XVI. Lisboa: Comissão Nacional para as Comemorações dos Descobrimentos Portugueses, 1999.

GODINHO, Vitorino Magalhães - Portugal: a emergência de uma Nação. Lisboa: Edições Colibri, 2004.

LANCIANI, Giulia; TAVANI, Giuseppe (org.) - Dicionário da Literatura Medieval Galega e Portuguesa. Lisboa: Caminho, 1993.

LIMA, Douglas Mota Xavier de - “A política matrimonial de D. João I: um instrumento de afirmação dinástica. Portugal, 1387-1430". Roda da Fortuna, Revista eletrônica sobre Antiguidade e Medievo, vol. 3, 2 (2014), pp. 193-195.

LIMA, Douglas Mota Xavier de - O Infante D. Pedro e as Alianças externas de Portugal (1425-1449). Niterói: Universidade Federal Fluminense, 2012. Dissertação de Mestrado.

MARQUES, Alfredo Pinheiro - A maldição da memória do Infante Dom Pedro e as origens dos descobrimentos portugueses. Figueira da Foz: Centro de Estudos do Mar, 1994. 
MARQUES, Alfredo Pinheiro - Vida e Obra do Infante D. Pedro. Lisboa: Gradiva, 1996.

MARQUES, António H. de Oliveira - Portugal na crise dos séculos XIV e XV. Lisboa: Presença, 1987.

MATTOSO, José (dir.) - A Monarquia Feudal. História de Portugal. Vol. II. Lisboa: Estampa, 1993.

MENÉNDEZ PIDAL, Ramón - "El compromisso de Caspe, autodeterminación de un pueblo (1410-1412)". in MENÉNDEZ PIDAL, Ramón (dir.) - Historia de España. Tomo XV. Los Trástamaras de Castilla y Aragón en el siglo XV. Madrid: EspasaCalpe, 1964, pp. IX-CLXIV.

MOREnO, Humberto Carlos Baquero - O Infante D. Pedro, Duque de Coimbra: itinerários e ensaios históricos. Porto: Universidade Portucalense, 1997.

OCHOA BRUN, Miguel Ángel - Historia de la Diplomacia Española. Vol 2. Madrid: Biblioteca Diplomática Española, 2003.

PINHO, Sebastião Tavares de - "O Infante D. Pedro e a "Escola" de tradutores da Corte de Avis". Actas do Congresso Comemorativo do $6^{\circ}$ Centenário da morte do Infante $D$. Pedro. Biblos. Revista da Faculdade de Letras - Universidade de Coimbra (1993), pp. 140-148.

QUEIRÓS, Silvio Galvão de - "Pera Espelho de Todollos Uiuos". A imagem do Infante D. Henrique na Crônica da Tomada de Ceuta. Niterói: Programa de PósGraduação em História da Universidade Federal Fluminense, 1997. Dissertação de Mestrado.

RODRIGUES, Ana Maria S. A. - “D. Leonor, Infanta de Aragão, Rainha de Portugal: linhagem, gênero e poder na Península Ibérica do século XV”. in Raízes medievais do Brasil moderno - Actas. Lisboa: Academia Portuguesa de História, 2008, pp. 209-232. 
SANTOS, Domingos Maurício Gomes dos - "O Infante D. Pedro na Áustria-Hungria". Brotéria. Revista Contemporânea de Cultura tomo LXVIII, Lisboa (1959), pp.17-37.

SERRÃO, Joel (dir.) - Dicionário de História de Portugal. Lisboa: Iniciativas Editoriais, 1975.

SILVA, Manuela Santos - "O casamento de D. Beatriz (filha natural de D. João I) com Thomas Fitzalan (Conde de Arundel) - paradigma documental da negociação de uma aliança”. in FARIA A. L.; BRAGA I. D. (org.) - Problematizar a História. Estudos de História Moderna em homenagem a Maria do Rosário Themudo Barata. Lisboa: Caleidoscópio, 2007, pp. 77-91.

SERRÃO, Joaquim Veríssimo - História de Portugal. Vol. II. Formação do Estado Moderno (1415-1495). Lisboa: Verbo, $2^{\mathrm{a}}$ edição, 1978.

SOARES, Nair de Nazaré Castro - "O Infante D. Pedro e a cultura portuguesa". Biblos. Revista da Faculdade de Letras - Universidade de Coimbra Vol. LXXVIII (2002), pp. 107-128.

SOUSA, Armindo de - "Condicionamentos básicos". in MATTOSO, José (dir.) - A Monarquia Feudal. História de Portugal, Vol. II. Lisboa: Estampa, 1993, pp. 311-389.

SUARÉZ FERNÁNDEZ, Luís - "Los infantes de Aragón y Don Álvaro de Luna”. in MENÉNDEZ PIDAL, Ramón (dir.) - Historia de España. Tomo XV. Los Trástamaras de Castilla y Aragón en el siglo XV. Madrid: Espasa-Calpe, 1964, pp. 69-122.

SUARÉZ FERNÁNDEZ, Luís - Nobleza y Monarquía. Entendimiento y Rivalidad. El proceso de la construcción de la coronã española. Madrid: La Esfera de los libros, 2005. 


\section{COMO CITAR ESTE ARTIGO}

\section{Referência electrónica:}

LIMA, Douglas Mota Xavier de - "À volta do casamento do infante D. Pedro".

Medievalista 21 (Janeiro-Junho 2017). [Em linha] [Consultado dd.mm.aaaa].

Disponível em

http://www2.fcsh.unl.pt/iem/medievalista/MEDIEVALISTA21/lima2106.html ISSN 1646-740X.

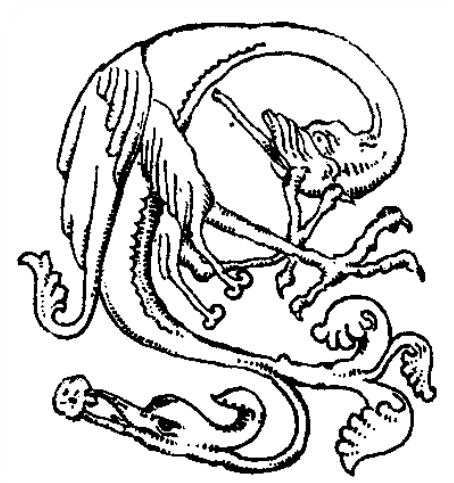

